\title{
TELETRANSMISSION AS A USEFUL METHOD IN THE CONDUCT OF MEDICAL RESCUE TEAMS
}

\author{
Artur Karpiarz $^{1,2}{ }^{(0)}$, Lukasz Czyzewski ${ }^{3,4}$ (1) \\ ${ }^{1}$ Student of Faculty of Health Sciences, Collegium Mazovia Innovative University, Siedlce, Poland \\ ${ }^{2}$ SP ZOZ "MEDITRANS" Emergency and Sanitary Transport Station in Siedlce, Siedlce, Poland \\ ${ }^{3}$ Department of Nephrology Nursing, Medical University of Warsaw, Warsaw, Poland \\ ${ }^{4}$ Faculty of Health Sciences, Collegium Mazovia Innovative University, Siedlce, Poland
}

\section{Abstract}

INTRODUCTION: Emergency medical services, during their activities, must diagnose conditions directly threatening the patient's life and health, implement appropriate procedures, secure the patient, and transport them to a place where they can be given more appropriate assistance in the shortest possible time. Performing teletransmission significantly reduces the time to provide the patient with proper, life-saving assistance. In this study the authors undertook an analysis of teletransmissions carried out by the teams of EMS. These data are to be used to assess the MRT activities depending on the hospital to which the patient was transferred.

MATERIAL AND METHODS: The information was obtained based on the analysis of MRT exit cards working in the area of the Sokołowski powiat and the city of Sokołów Podlaski. The author analysed 3804 travel cards of the MRT 04-51, 04-52, 04-54 teams in Sokołów Podlaski and Kosów Lacki in 2018, distinguished 147 cards during which the teams performed teletransmission to the Haemodynamics Centre in Siedlce. Then the exit cards were analysed according to the patient's age, and then the time elapsed from departure to arrival at the place of call and from arrival to the moment of transferring the patient to the hospital, broken down by urgency code of departure: code 1 (C1) and code 2 (C2). P $<0.05$ was adopted as the significance level.

RESULTS: The average age of teletransmitted patients was $69.8 \pm 17$ years, and the average age without teletransmission was $65.8 \pm 23.6$ years $(p=0.042$ ). The time elapsed from reaching the patient to the time of transfer in the hospital for patients who were teletransmitted was $49.1 \pm 16.1$ minutes, and for patients who were not it was $39 \pm 22.2$ minutes $(p<0.001)$. The average time to reach the patient in the code 1 was $10.9 \pm 7.4$ minutes, and in the code 2 it was $14.5 \pm 17.9 \mathrm{~min}(p<0.001)$. It was shown that the patient's age did not affect the time of departure and arrival at the place of call $(r=0.075)$, nor the time of transferring the patient to the hospital $(r=0.027)$.

CONCLUSIONS: 1. The results obtained show the need to perform the teletransmission procedure as soon as possible and to apply appropriate treatment by MRT. This can significantly reduce the time to balloon a clogged vessel or attach a stent.

2. Performing teletransmission extends the time of patient transfer in hospital by nearly 10 minutes

3. Considering the place of patient transfer in ER or ED, both the age of the patients, times from the MRT departure to arrival at the call site, and the time from arrival at the place of call to transfer in hospital turned out to be statistically significant.

KEY WORDS: Emergency Medical Services, teletransmission, Sokołów Country, paramedic, electrocardiogram

Disaster Emerg Med J 2020; 5(2) 


\section{INTRODUCTION}

Cardiological problems are among the most common reasons for calling emergency medical services (EMS) in the US, Europe, and Poland. Calls due to cardiological problems include chest pain, palpitations, fainting, fainting, shortness of breath, high blood pressure, and sudden cardiac arrest. EMS, during their activities, must make the diagnosis of conditions directly threatening the patient's life and health, implement appropriate procedures, secure the patient, and transport them to a place where they will be given more appropriate assistance in the shortest possible time, in accordance with the "golden hour rule". In Poland, among all deaths, cardiovascular diseases account for $45 \%$ [1].

Medical rescue teams (MRT) referring the patient to the emergency room (ER), hospital emergency department (ED), or directly to the haemodynamics centre (to perform percutaneous coronary intervention or fibrinolytic therapy implementation) by coding the diagnosis, most often choose disease entities such as chest pain, acute coronary syndrome (ACS), hypertension, atrial fibrillation, shortness of breath, heart attack, and more. Paramedics, physicians reaching the patient in a state of sudden threat to health as part of their activities, in accordance with medical art and the recommendations of the European and Polish Resuscitation Council, should perform a number of diagnostic tests and procedures to determine and diagnose the patient's problems.

The most commonly used are:

1. Blood pressure measurement (NIMB);

2. Heart rate measurement (HR);

3. Measurement of blood saturation $\left(\mathrm{SpO}_{2}\right)$;

4. Performing an electrocardiogram (ECG);

5. Performing ECG teletransmission to the haemodynamics centre;

6. Blood glucose measurement.

\section{Myocardial infarction with ST segment elevation and without ST elevation}

The heart muscle consumes about $40 \%$ of the body's oxygen demand. If this oxygen is lacking or there is narrowing of the lumen of the coronary vessel (spasm, clogging with atherosclerotic plaque), there is chest pain. The pain that occurs after exercise is caused by a reduced blood flow through the heart muscle vessel and indicates angina pectoris. After cessation of effort, the pain also subsides. In the event that the coronary vessel is completely clogged and the pain does not go away either when exercising is stopped or nitroglycerin (NTG) is taken, we are talking about ACS. When acute coronary syndrome is confirmed by 12-lead ECG and/or cardiac

\section{Teletransmission and proceedings}

The primary task of MRT in patients with chest pain is to diagnose STEMI. Travel teams, after conducting an interview, examining a patient, and performing an ECG, evaluate his/her record in order to determine the diagnosis and start proper treatment and transport to the hospital. Medical history may be based on the SAMPLE acronym:

$S$ - symptoms (ailments), e.g. type of pain, how long it lasts, location;

A - allergies, possible allergy to drugs, foods;

$\mathrm{M}$ - medications, medications taken so far;

$\mathrm{P}$ - past diseases, especially in this case of the heart, circulation;

$\mathrm{L}$ - lunch, when and what patient has recently eaten; E - possibly, what happened and other symptoms, e.g. shortness of breath, oedema [3].

The physical examination most often states the following: pallor of the coatings, sweats, tachycardia, and hypotension. Then perform a 12-lead ECG, preferably up to 10 minutes after arriving at the patient and transfer to a suitable centre. To avoid an error in diagnosis, at the pre-hospital stage it is necessary to support teletransmission of a record to the haemodynamic institution and consultation with a cardiologist, and jointly establish patient management [4]. A member of the MRT, most often the manager, sends a full ECG recording using a telephone connected to the defibrillator, then makes a phone call and notifies the doctor and provides information about the patient's condition (Fig. 1). The receiving physician analyses the record and, in the case of STEMI or recent left bundle branch block, recommends transporting the patient to the haemodynamic laboratory, prescribing pharmacotherapy [4].

A patient qualified to the haemodynamic unit for peripheral reperfusion is subjected to percutaneous coronary angioplasty (PCA) or fibrinolysis [5].

Performing teletransmission significantly reduces the time to provide the patient with proper, life-saving assistance.

In this study the authors undertook an analysis of teletransmissions carried out by the teams of MRT Medical Emergency and Sanitary Transport Station RM "MEDITRANS" in Siedlce and its substation in Sokołów Podlaski. These data are to be used to assess the MRT activities depending on the hospital to which the patient was transferred. 


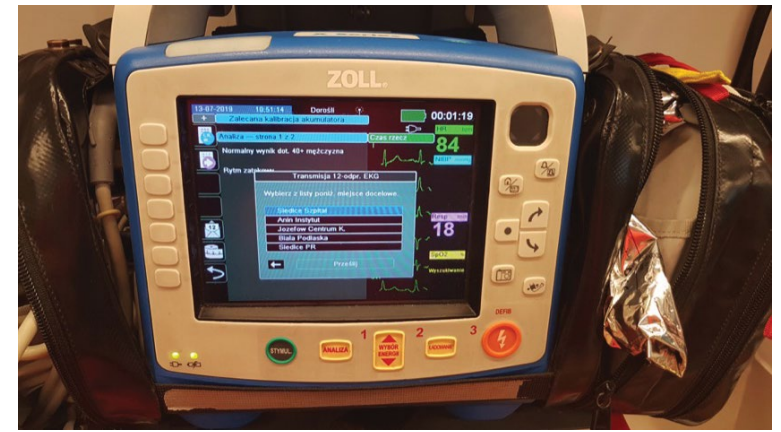

FIGURE 1. Sending ECG by MRT to the Haemodynamics Centre at the Mazowieckie Provincial Hospital in Siedlce

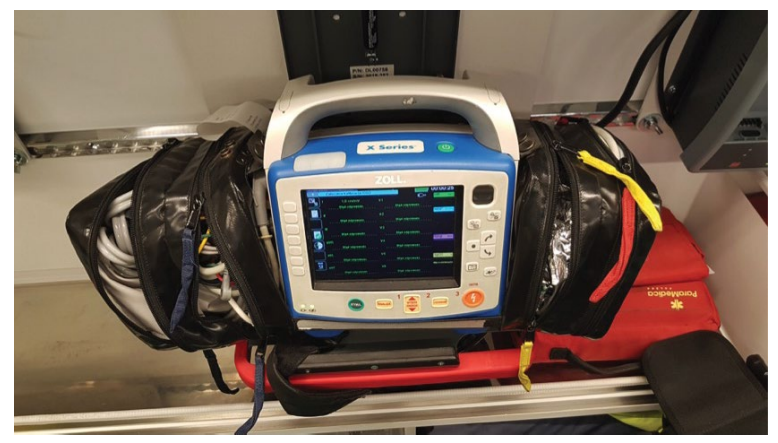

FIGURE 2. ZOLL X series defibrillator equipped with "S" assembly, no. W04-51

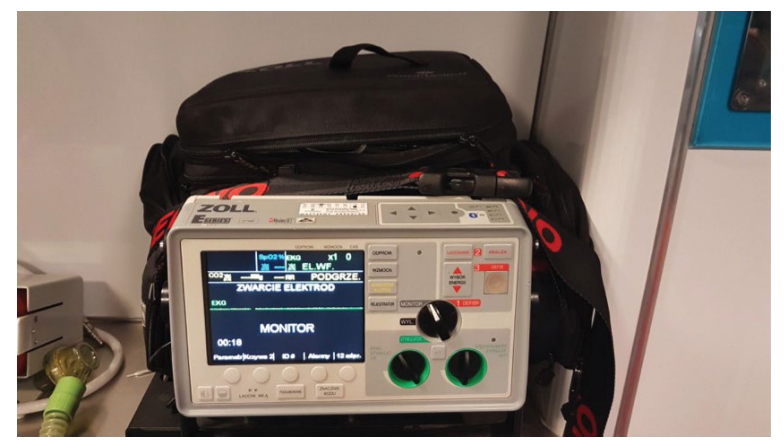

FIGURE 3. ZOLL E series defibrillator, included in B-MRT - W0452 and W04-54 equipment

\section{MATERIAL AND METHODS}

The information was obtained based on the analysis of MRT exit cards working in the area of the Sokołowski powiat and the city of Sokołów Podlaski. The consent of the director of SP ZOZ "MEDITRANS" Emergency and Sanitary Transport Station in Siedlce was given for access to exit cards and statistical data. The study conformed to the principles outlined in the Declaration of Helsinki. All data were analysed anonymously with no possibility of identifying individual patients. The acquired data is anonymous in terms of patient data as well as personal data of MRT members. The author analysed 3804 travel cards of the MRT 04-51, 04-52, and 04-54 teams in Sokołów Podlaski and Kosów Lacki in 2018, and distinguished 147 cards during which the teams performed teletransmission to the Haemodynamics Centre in Siedlce.

Then the exit cards were analysed according to the patient's age, and then the time elapsed from departure to arrival at the place of call and from arrival to the moment of transferring the patient to the hospital, broken down by urgency code of departure: code 1 (C1) and code 2 (C2). The next step was analysis in terms of the place of transfer of the patient: ER or ED.

\section{Characteristics of the Sokołów powiat and the city of Sokołów Podlaski}

The Sokotów powiat was inhabited by 54,797 inhabitants, of whom $50.5 \%$ were women and $49.5 \%$ were men. The average age of residents was 42.2 years, which was comparable to the average age of residents of the Mazowieckie voivodship. In 2016, 49.9\% of deaths in the Sokołowski powiat were caused by cardiovascular diseases, $20.3 \%$ of deaths were due to cancer, and $9.1 \%$ of deaths were caused by respiratory diseases [6].

\section{Characteristics of EMS in the Sokołów County}

There are three MRTs operating in the Sokolowski powiat, including one specialist team (S) operating round the clock, which includes a medical doctor, paramedic, and medical rescuer - a driver who is stationed in the city of Sokołów Podlaski, one basic team (B) operating 10.00-22.00, which consists of a paramedic or system nurse, acting as team leader, a paramedic, and a paramedic/driver who is also stationed in the city of Sokołów Podlaski. The last MRT is the B team stationed in Kosów Lacki, operating around the clock, consisting of a paramedic or system nurse, acting as a team leader, as well as a paramedic and paramedic/driver.

The S-MRT team is equipped according to the specifications of the National Health Fund (NHF) with patient monitoring equipment, devices, transport, and teletransmission (ZOLL X-series) - Figure 2. B-MRT teams, also equipped in accordance with the NFZ requirements. Defibrillators also equipped with ZOLL E series defibrillators (Fig. 3, 4) 


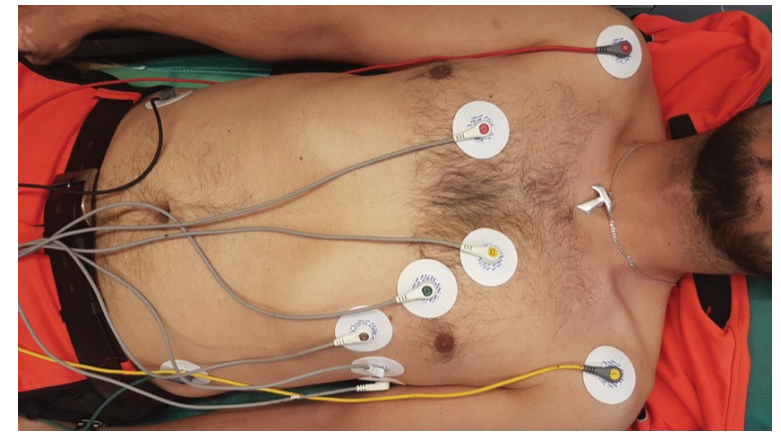

FIGURE 4. Placement of precordial and limb electrodes on the patient's body

\section{Statistical analysis}

Results concerning quantitative variables were presented as average values \pm standard deviation. Qualitative variables (age, sex) were presented as quantity (n) and percentage values of the whole group (\%). Student's t-test was applied to compare the different times and to determine the statistical difference for each group. In the comparative analysis of age and the time of transferring the patient to the hospital, simple linear regression analysis (Spearman) was applied to detect and describe the strength and direction of correlations of clinical data. Statistica 13.3 software (Tibco Inc., Tulsa, USA) was used in the statistical analysis. $\mathrm{P}<0.05$ was adopted as the significance level.

\section{RESULTS}

Table 1. presents the results of the comparative analysis of patients with teletransmission. The average age of teletransmitted patients was $69.8 \pm 17$ years, and the average age without teletransmission was $65.8 \pm 23.6$ years - a statistically significant difference was shown $(p=0.042)$. In the group of patients who were teletransmitted, the time of commuting to the patient was $13.5 \pm 8.7$ minutes and the time of arrival to the place of call to patients who were not teletransmitted was also on average $13.5 \pm 16.1$ minutes - no statistically significant difference was shown $(p=0.955)$. The time elapsed

Table 2. Univariate comparison of patients with
urgency code of departure
\begin{tabular}{|l|c|c|c|}
\hline & Code 1 & Code 2 & \multirow{2}{*}{$\mathrm{p}$} \\
\cline { 2 - 3 } & $\mathrm{n}=1021$ & $\mathrm{n}=2813$ & \\
\hline Age [y] & $62.5 \pm 26.0$ & $67.3 \pm 22.3$ & $<0.001$ \\
\hline $\begin{array}{l}\text { Departure Time- } \\
\text { Arrival [min] }\end{array}$ & $10.9 \pm 7.4$ & $14.5 \pm 17.9$ & $<0.001$ \\
\hline $\begin{array}{l}\text { Arrival Time- } \\
\text { Handover [min] }\end{array}$ & $37.1 \pm 19.3$ & $40.9 \pm 22.9$ & $<0.001$ \\
\hline
\end{tabular}

from reaching the patient to the time of transfer in the hospital for patients who were teletransmitted was $49.1 \pm 16.1$ minutes and for patients who were not it was $39 \pm 22.2$ minutes, which showed a statistically significant difference $(p<0.001)$.

Table 2 . analyses the data broken down by urgency code 1 and code 2 trips. The average time to reach the patient in $\mathrm{C} 1$ was $10.9 \pm 7.4$ minutes and in C2 $14.5 \pm 17.9$ min - a statistically significant difference was shown $(p<0.001)$. In the $C 1$ code, the average time from the team's arrival to the place of call to the patient's transfer to the hospital was $37.1 \pm 19.3$ minutes, and in the $C 2$ code the average time was $40.9 \pm 22.9$ minutes - a statistically significant difference was found $(p<0.001)$. The average age in C1 was $62.45 \pm 26.04$ years, and in C2 the average age was $67.25 \pm 22.25$ years - a statistically significant difference was found $(p<0.001)$.

The age of the patients, depending on the place of transfer of the patient to the hospital in which the ER or ED operates, as follows: The average age of the patient transferred to the ER was $67.0 \pm 22.5$ years and in the ED $62.7 \pm 26.7$ years $(p<0.001)$. Analysis of the time from the MRT departure to arrival at the call site showed the average time of patients transferred in ER $13.4 \pm 9.0$ minutes and transferred in ED $14.7 \pm 9.3(p=0.014)$; the average time from arrival at the place of call to transfer in ER was $38.8 \pm 17.0 \mathrm{~min}$; and the mean time to refer in the ED was $64.0 \pm 17.4 \min (p<0.001)-$ see Table 3.

Table 1. Univariate comparison of patients with teletransmission

\begin{tabular}{|l|c|c|c|}
\hline & Without teletransmission & Teletransmission & \multirow{2}{*}{$\mathrm{p}$} \\
\cline { 2 - 3 } & $\mathrm{n}=3682$ & $\mathrm{n}=147$ & 0.042 \\
\hline Age [y] & $65.8 \pm 23.6$ & $69.8 \pm 17.0$ & 0.955 \\
\hline Departure Time-Arrival [min] & $13.5 \pm 16.1$ & $13.5 \pm 8.7$ & $<0.001$ \\
\hline Arrival Time-Handover [min] & $39.5 \pm 22.2$ & $49.1 \pm 16.1$ & $<$ \\
\hline
\end{tabular}




\begin{tabular}{|c|c|c|c|}
\hline & ER & ED & \multirow{2}{*}{$p$} \\
\hline & $n=2685$ & $n=296$ & \\
\hline Age [y] & $67.0 \pm 22.5$ & $62.7 \pm 26.7$ & $<0.001$ \\
\hline $\begin{array}{l}\text { Departure Time- } \\
\text { Arrival [min] }\end{array}$ & $13.4 \pm 9.0$ & $14.7 \pm 9.3$ & 0.014 \\
\hline $\begin{array}{l}\text { Arrival Time- } \\
\text { Handover [min] }\end{array}$ & $38.8 \pm 17.0$ & $64.0 \pm 17.4$ & $<0.001$ \\
\hline
\end{tabular}

It was shown that the patient's age did not affect the time of departure and arrival at the place of call $(r=0.075)$ or the time of transferring the patient to the hospital $(r=0.027)$

\section{DISCUSSION}

For several years, research has been being conducted into the usefulness of early teletransmission by MRT. In the current era of development of technology, the Internet, and electronics, the amount of data transferred directly from the place where the patient is found to specialised treatment centres of particular importance from the point of view of health and life of disease states is growing. Among the most important, Piotrowicz et al. [8] in the article "Telemedicine - changes in the process of providing cardiological services. Possibilities and realities" presented ECG teletransmission, which was introduced as one of the earliest into practice. It is used in patients with suspected ischaemia and arrhythmias, with previously detected arrhythmias, and with a risk of serious arrhythmias including myocardial infarction and fainting. According to the authors of the article, the most important aspect is having the correct diagnosis, but also early therapeutic intervention, which is important for the entire health care system, both temporarily and financially, increasing the chance for adequate treatment.

Also very important from the point of view of sending ECG teletransmission was the study of Karcz et al. [9], which covered the eastern part of the Mazowieckie and northern Lubelskie voivodeships. The study was the result of a management model created in 2003 to reduce the time to perform PPCl bypassing the nearest hospital and transporting patients to the haemodynamics laboratory. The study included 856 patients who had teletransmission, from this group from ED, 267 people were admitted to the Institute of Cardiology in Anin, including 214 from STEMI. It was a pilot program that was to implement MRT to use teletransmission. It was noted that every month the STEMI percentage as a result of ECG transmission was about $30 \%$.

Obłój et al. [10], in a retrospective analysis, analysed 13,534 exit cards of MRT in the Olecki powiat in the years 2012-2015. From among all the trips they separated patients with cardiovascular diseases, and among them patients with acute myocardial infarction were analysed. They showed that $2 \%$ of the total number of patients was transported to the invasive cardiology centre. Among people with cardiovascular disease, $64 \%$ were men with an average age of 63 years, and the average age of women was 71 years. $58 \%$ of patients with cardiovascular disease went to the Centre of Invasive Cardiology with the diagnosis of acute myocardial infarction. The authors showed that the average time from accepting an application to forwarding for invasive cardiology was 63 minutes. In the analysed period, MRT performed 489 ECG teletransmissions.

Stępka [11] analysed 205 ECG teletransmissions performed by the local MRT to the Allenort Cardiology Centre in Kutno, performed from March 2010 to December 2012. It was noticed that the majority of teletransmissions were performed by B-MRT. In the records sent by the B team most often His left bundle branch block (5\%) and $I^{\circ}$ atrioventricular block $(25 \%)$ were diagnosed, as well as $\mathrm{S}$ syndromes left bundle branch block (19.05\%), His bundle branch block (19.05\%), and atrioventricular block I ${ }^{\circ}(19.05 \%)$. However, not all teams around Kutno used teletransmission; one of the teams used it in $0.09 \%$ of trips and the other in $0.16 \%$.

An analysis of ambulance trips in the Sokołowski powiat shows that teletransmission plays a significant role at work. Over the period considered, $49.9 \%$ of deaths were caused by cardiovascular diseases. Therefore, patients with chest pain, shortness of breath, and cardiac history should have teams in the $\mathrm{C} 1$ urgency code, especially because the nearest haemodynamic laboratory is located in Siedlce, $28 \mathrm{~km}$ away. MRTs from the furthest cities often transport patients to the hospital for more than an hour, adding to this the travel time, an average of 13.5 minutes, and the time to perform teletransmission (10 minutes) is too long, above the "golden hour" waiting time for patients to receive proper help. Certainly, placing an ambulance in places such 
as Jabłonna Lacka, Skrzeszew would significantly reduce the travel time to patients. Teletransmission activities could be carried out in an ambulance, especially because in further locations, among the forests, MRT have frequent problems with the range of the telephone network that is used for ECG transmission. This involves a risk to the safety of the ambulance staff, with possible braking when the test persons are not fastened with seat belts.

\section{CONCLUSIONS}

1. The results obtained show the need to perform the teletransmission procedure as soon as possible and for the MRT to apply appropriate treatment. This can significantly reduce the time to balloon a clogged vessel or attach a stent.

2. Performing teletransmission extends the time of patient transfer in hospital by nearly 10 minutes.

3. Considering the place of patient transfer in an ER or ED, the age of the patients, time from the MRT departure to arrival at the call site, and the time from arrival at the place of call to transfer in hospital turned out to be statistically significant.

4. The time from the arrival at the place of call to transfer in the Emergency Room was longer by 25.26 minutes compared to the Emergency Room. This is closely related to the fact that ambulances transporting patients to the Emergency Room in Siedlce had a $28 \mathrm{~km}$ longer route to travel.

5. The age of the patients to whom ambulances were called in $\mathrm{C} 1$ was almost 5 years lower than the age of patients in $\mathrm{C} 2$.

6. The travel time in $\mathrm{C} 1$ was shorter than in $\mathrm{C2}$, as was the time of transferring the patient to the hospital, in both cases by almost 4 minutes.
Acknowledgments: The authors are very grateful to the Director of "RM MEDITRANS" Rescue and Emergency Transport Station in Siedlce for making the ambulance call reports available.

Conflict of interest: The authors declare that they have no conflicts of interest. None of the authors involved in this study have any financial relationship.

Source of support: No sources of financial or material support to be declared.

\section{REFERENCES:}

1. Niewiadomski J. Teletransmisja zapisu EKG - wsparcie, przymus czy niepotrzebny wydatek. Na Ratunek. ; 2013: 4.

2. Szczeklik A. Internal Medicine. Kraków, Medycyna Praktyczna. ; 2011.

3. Paciorek P, Patrzała A. Medical emergency operations. Warszawa : Wydawnictwo Lekarskie PZWL. ; 2015.

4. Preisz P. Acute coronary syndromes. Emergency Medicine. 2009: 108-121, doi: 10.1016/b978-0-7295-3876-3.10007-3.

5. Nikolaou N, Arntz HR. Resuscitation guidelines 2015. Kraków : Polska Rada Resuscytacji. ; 2016.

6. http://www.polskawliczbach.pl/powiat sokolowski.

7. http://www.rmmeditrans.pl.

8. Piotrowicz $R$, Balsam $P$, Grabowski $M$, et al. Telemedicine - changes in a way of delivering medical services. Nauka. 2016; 4: 53-69.

9. Karcz M, Bekta P, Skwarek M, et al. Rozpowszechnienie teletransmisji EKG w przedszpitalnym postępowaniu z chorymi z podejrzeniem ostrego zawału serca - efekty programupilotażowego POLKARD na wschodnim Mazowszu. Postępy w kardiologii interwencyjnej. 2006; 2: $274-280$.

10. Obłój D, Zalewski J, et al. Wróblewska I Medical rescue team activities with patients diagnosed with acute coronary syndrome. Anestezjologia i ratownictwo. 2017; 11: 273-281.

11. Stępka A. Analiza teletransmisji danych elektrokardiograficznych. Na Ratunek czasopismo dla służb ratujących życie. 2013; 1: 43-50. 